\title{
US half-rate goal in dispute
}

\section{Washington}

THE National Cancer Institute (NCI) continues to defend its "achievable" goal of halving US age-adjusted cancer mortality by the year 2000 , first announced (to great dramatic effect) before the US Senate appropriations committee in April this year. But NCI has yet to make public any detailed justification for this claim, and its feasibility has been questioned. $\mathrm{NCI}$ plans to publish a full description of its year 2000 programme in 2 or 3 months, after review by the National Cancer Advisory Board.

Since 30 per cent of the 440,000 deaths from cancer each year in the United States are attributable to cigarette smoking, all agree that curtailing smoking is crucial. NCI's provisional estimate is that it should be able to halve lung cancer mortality by 2000 by preventive measures alone. But there are doubts whether NCI can achieve the 50 per cent reduction in smoking over the ten years to 1990 needed for this target.

As a government agency, NCI is prevented from lobbying for what is known to be one effective means of reducing smoking: higher taxes on cigarettes. NCI's weakness on this score was underlined in the summer, when Congress voted to lower cigarette taxes as part of a compromise that included strengthening the health warning on cigarette packets. For the same reason, NCI cannot take a position on, for example, banning cigarette advertising or restricting smoking in public places. And NCI's own advertising efforts are limited to free "public service" air time donated by radio and television stations and pamphlets distributed in physicians' waiting rooms. The emphasis is on helping only those who want to stop smoking, rather than encouraging confirmed smokers to reform.

Even if smoking could be halved by 1990 , success in halving lung cancer by the end of the century would be far from assured. While smoking appears still to be decreasing among males, there are signs that it is increasing among females, and such reductions in smoking as there have been in recent years have been restricted to the higher socioeconomic classes. In order to reach the target, the $\mathrm{NCI}$ programme would have to be effective among the older/heavier smokers who are most at risk but the hardest to convert, according to Dr John Higginson of Universities Associated for Research and Education in Pathology. Dr Lewis Kuller, director of the department of epidemiology at the University of Pittsburgh, goes further, saying that the year 2000 goal on lung cancer will be achievable only if a chemopreventative agent is discovered for treatment of those who have stopped smoking.

The target is defended by Dr Joseph Cullen of NCI. The institute is about to embark on large-scale intervention trials that will include 10 million subjects over 5 years, designed the better to define how to persuade people to stop smoking. There will be a special programme for high-risk groups, and physicians will be trained in anti-smoking counselling. Cullen predicts that $\mathrm{NCI}$ will extend its influence with policy-makers and the media, and that the continuing shift in public attitudes will be helped by, for example, boycotts against magazines that carry cigarette advertising. Cullen will not be drawn on how NCI will get around the statutory limits on its authority except to say that more federal and state funds will have to be used.

Smoking aside, NCI plans to achieve a further 15 per.cent reduction in cancer mortality by the year 2000 by ensuring full public access to state-of-the-art treatment. Dr Peter Greenwald, director of NCI's division of cancer prevention and control, says this target makes no allowance for advances in treatment yet to be discovered or for earlier detection, but that it is based on treatments now at the stage of clinical trials. On top of the reduction due to improved access, Greenwald anticipates another 15 per cent reduction due to improved treatment of micrometastases; he points to experimental treatments using monoclonal antibodies targeted at specific oncogene products. While acknowledging that the figures might be disputed by a conservative statistician, Greenwald stresses the importance of having goals.

Others doubt whether these dramatic predictions can be defended. While more widespread screening programmes could markedly reduce breast cancer mortality (possibly by up to 30 per cent), and perhaps cervical cancer also, the other major killers seem stubbornly resistant to improved treatment. Kuller says he "would have difficulty being convinced" that these improvements are in prospect without further major advances in early detection. Tests for cancers of the gastrointestinal tract, for example, are still much needed.

Perhaps the most controversial element of NCI's year 2000 plan is the goal of reducing mortality by 5 per cent by changing eating habits. While interpopulation comparisons indicate that up to 35 per cent of cancers may be caused by dietary factors, the precise components involved are not known. Despite the small number of studies of fibre intake and cancer, NCI's director, Dr Vincent DeVita, told the Senate Appropriations Committee in April that a doubling of fibre intake could reduce colon cancer by 30 per cent by the year 2000. NCI also now believes that a reducing fat consumption will help.

Others are not so sure: Kuller says the 5 per cent target "could be wishful thinking'. In 1982, the National Academy of Sciences concluded that it was impossible to quantify the likely effect on cancer incidence of dietary changes. Higginson believes the effect of diet on cancer incidence in adults has been exaggerated, and points out that the reductions in fat consumption seen in recent years, which have had a marked effect on heart disease, have so far failed to have the effect on cancer incidence that would be expected according to the simple dietary hypotheses, thus making the overall NCI target even less realistic.

Tim Beardsley

\section{European environment}

\section{Hopes to reform farming}

Brussels

THE European Community may be about to mount a vast new programme of research and development in agrochemicals. That, at least, is what will happen if the commissioner for environment and internal market affairs, Mr KarlHeinz Narjes, gets his way. At a conference in Dublin two weeks ago, Mr Narjes argued that pesticides and fertilizers have had an undesirable effect on the environment, and that the time has now come to encourage technical innovation to yield more selective but less persistant pesticides.

The environment commissioner has been trying for some time to persuade his colleagues in the commission that environment policies should be integrated with others, and with agricultural policy in particular. Formally, this principle is written into the current action plan on the environment. Now there are signs that the member states are coming round to Mr Narjes's way of thinking.

Mr Narjes is not anti-farmer. Instead, his aim is that agriculture should continue to profit from the use of chemicals without putting an intolerable burden on the environment. In Dublin, he was pleading for more work on the toxicology of pesticides, allowance for regional and national differences of cultivation techniques and a training programme for farmers.

Within the Community, the Dutch Government has already advocated the use of European Community funds to protect the environment linked to farming in lessfavoured areas. Meanwhile, the United Kingdom, backed by Ireland, has been urging that Community agricultural funds should be made available to farmers for "environmentally friendly actions".

The outlook for Community regulation of agricultural pollution seems less bright, however. Member states have been unable to agree on a list of acceptable pesticides since 1976, while proposals for maximum permitted levels of pesticides in foodstuffs have been gathering dust since 1981 . $\mathrm{Mr}$ Narjes seems bent on circumventing the regulatory log-jam by tackling the problem at source.

Anna Lubinska 